\title{
Erratum to: Evidence for dispersal and habitat controls on pond diatom communities from the McMurdo Sound Region of Antarctica
}

\author{
A. Sakaeva ${ }^{1}$ - E. R. Sokol ${ }^{1}$ T. T. Kohler ${ }^{2}$ L. F. Stanish ${ }^{1}$ - S. A. Spaulding ${ }^{1}$. \\ A. Howkins ${ }^{3}$ - K. A. Welch ${ }^{4}$ - W. B. Lyons ${ }^{4}$ J. E. Barrett ${ }^{5}$ - D. M. McKnight ${ }^{1}$
}

Published online: 26 April 2016

(C) Springer-Verlag Berlin Heidelberg 2016

\section{Erratum to: Polar Biol \\ DOI 10.1007/s00300-016-1901-6}

In the original publication, five sites $(12,13,14,19$, and 20) are mislabeled on Fig. $2 x$-axis due to an error replacing site names with site codes as part of the revision. Specifically, the data presented for site 14 actually belongs to site 12 (Pony Lake), site 12 data belong to site 13 (MCM lower), and site 13 data belong to site 14 (MCM upper). Furthermore, data for 19 (Parera Pond) and 20 (Picture Pond) should be switched. This error is confined to the $x$-axis labels of Fig. 2 and does not affect other figures nor the conclusions made by the paper. The corrected Fig. 2 is presented below.

The online version of the original article can be found under doi:10.1007/s00300-016-1901-6.

$\triangle$ T. J. Kohler

tyler.j.kohler@gmail.com

$\triangle$ D. M. McKnight

diane.mcknight@colorado.edu

1 Institute of Arctic and Alpine Research, University of Colorado, 1560 30th Street, Boulder, CO 80303, USA

2 Department of Ecology, Faculty of Science, Charles University in Prague, Viničná 7, 12844 Prague 2, Prague, Czech Republic

3 Department of History, Colorado State University, 1372 Campus Delivery, Fort Collins, CO 80523, USA

4 Byrd Polar Research Center, The Ohio State University, 1090 Carmack Rd, 108 Scott Hall, Columbus, OH 43210, USA

5 Department of Biological Sciences, Virginia Tech, 1405 Perry Street, Blacksburg, VA 24061, USA 
Fig. 2 Dot plot representation of relative abundance counts averaged by water body. Site numbers are on the $x$-axis, and species names are on the $y$-axis. The size of a dot is proportional to the average relative abundance of a particular species as indicated in the legend. Note that sites 22-24 correspond to samples from Labyrinth Ponds 1-3 that contained no diatoms and have been omitted. See Table 1 for site numbers and Table 2 for species abbreviations

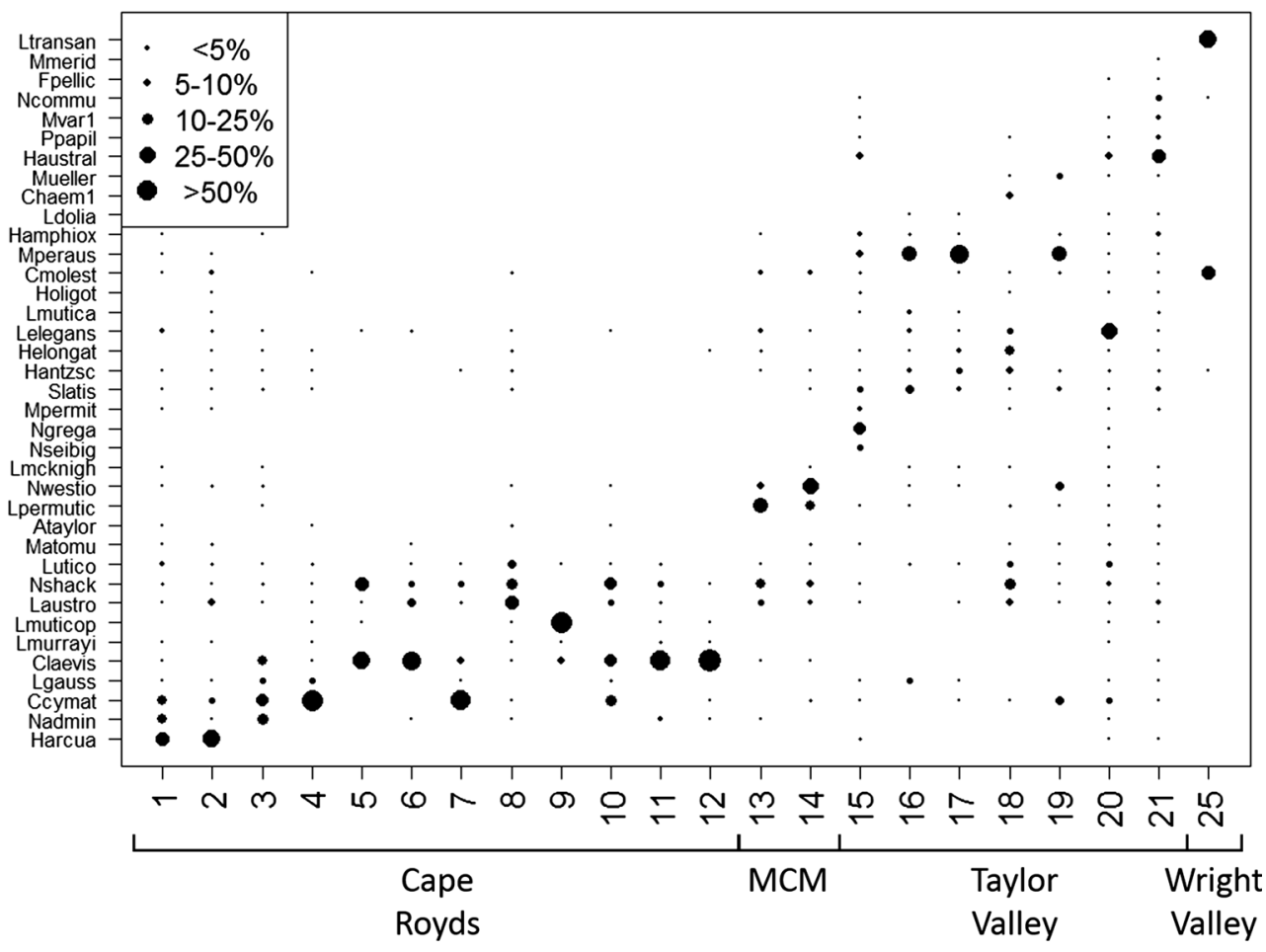

